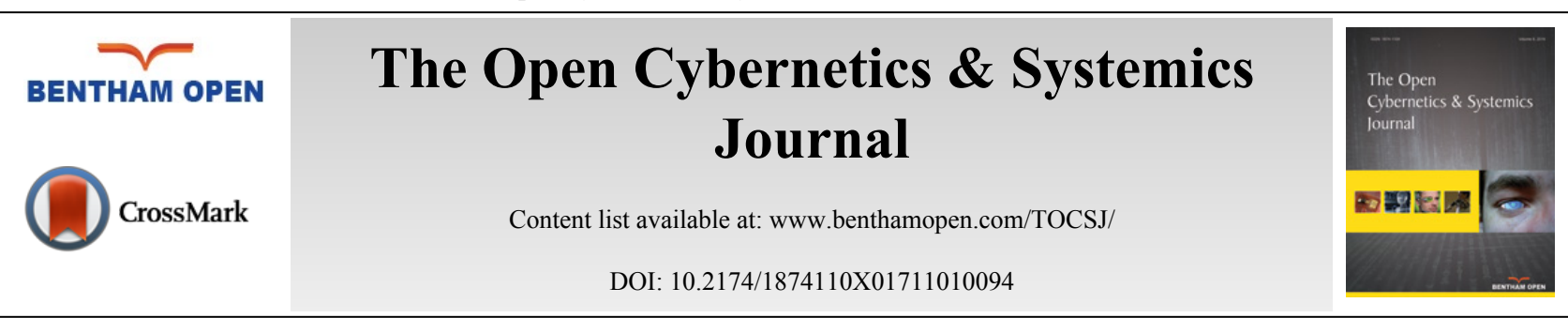

RESEARCH ARTICLE

\title{
The Analysis of Environmental Conflict in Changzhou Foreign Language School Using a Hybrid Game
}

\author{
Sharafat Ali, Haiyan $\mathrm{Xu}^{*}$, Peng $\mathrm{Xu}$ and Shinan Zhao \\ College of Economics and Management, Nanjing University of Aeronautics and Astronautics, Nanjing Jiangsu 211106, \\ P.R China
}

Received: December 04, 2016

Revised: February 22, 2017

Accepted: March 06, 2017

\section{Abstract:}

Background:

The brownfield convalescence conflict just happened in Changzhou, China in 2016 between local government and public.

\section{Objective:}

This paper aims to analyze the brownfield convalescence conflict based on the graph model for conflict resolution.

\section{Method:}

This paper uses the hybrid model combining the game and hypergame together.

\section{Results:}

The equilibria were obtained using the first level and the second level games.

\section{Conclusion:}

The proposed hybrid game provides a profound insight into the different aspects of the conflict and provides some policy implications and guidelines for the future environmental management.

Keywords: Environment, Soil pollution, Hypergame, Conflict Resolution, Nash Equilibrium, GMCR.

\section{INTRODUCTION}

Many economies, in pursuance of achieving environmental sustainability objectives, have adopted brownfield remediation strategy for urban land use. Brownfield is an abandoned or idled land formerly used as industrial site which is complicated enough to remediate $[1,2]$. The pursuit of higher economic trajectory exerted a heavy toll on the environmental quality. The increase in population coupled with rampant urbanization warrants more land utilization so the remediation of the brownfields has become necessary to utilize abandoned land for housing or business purposes. Brownfield redevelopment is not only useful in humanizing urban quality of life but some socioeconomic benefits such as cleanup of polluted land resulting in increased land value, job creation and tax-base expansion are also associated with it [3]. Industrial and anthropogenic pollution, as did in western economies, has also contaminated a large area of land in China. The relocation of dirty industries and chemical plants to new industrial areas resulted in abandoned and idle but contaminated land. About 16 percent of the Chinese soil is polluted with heavy metals and noxious chemical substances as claimed in soil-pollution survey and about 34.9 percent of the brownfields, outstandingly, have been

\footnotetext{
* Address correspondence to this author at the College of Economics and Management, Nanjing University of Aeronautics and Astronautics, No.29 Jiangjun Road, Jiangning District, Nanjing 211106, P.R China; Tel: +86 13951761103; E-mails: xuhaiyan@nuaa.edu.cn, xuhaiyan63@hotmail.com
} 
found to hold pollution levels higher than that of the national standards [4]. Convalescence of these polluted soils is necessary to avoid any environmental catastrophe. The remediation process varies with the type of pollution. Soil pollution unlike air or water pollution needs proper technique and equipment for remediation. Moreover, transparent, unbiased and comprehensive information about the sites and their levels of contamination is very hypercritical for the public awareness in terms of urban planning, in general, and for the brownfield remediation in specific.

The remediation without proper and appropriate information about the concentration and severity of the contaminations ends up in insufficient restoration of the environment and the noxious pollutants persist in to peril the environmental quality. This happened in Changzhou city of Jiangsu province, China. About 500 students of the Changzhou Foreign Language School (CFLS), built near former chemical plants, suffered from health problems sourced from improper acts taken in the remediation of the abandoned chemical industrial site [4, 5]. The local government launched a remediation project but the objectives of the project could not be achieved. In the meanwhile, the local government allowed the CFLS authorities to establish school next to the incompletely remediated brownfield. The public was not aware of the seriousness of the environmental contamination and its consequences so there was no serious appeal, by the public, for the full remediation of the brownfield. Consequently, soon after the relocation of the CFLS, there was an outbreak of adverse ailments in the school students. There has been a heated debate on electronic, print and social media after the telecast of the China Central Television (CCTV) channel report about Changzhou environmental catastrophic tragedy on April 16, 2016. The report became viral on internet in hours not only in China but also globally. The public outraged and demonstrated not only in Changzhou but all over China. The public appealed for the independent and impartial inquiry into the matter and full remediation of the brownfield area [5 - 8].

Formal conflict analysis tools and models have been developed to help the decision makers and stakeholders to analyze the impacts of their decisions providing insight during the negotiation process of the conflict. The Graph Model for Conflict Resolution (GMCR) approach to conflict analysis, as compared to other conflict models, requires only relative preference information that provides a more convenient and effective means to model and analyze a strategic conflict [9]. Game theoretic models are very useful for the analysis of environmental conflicts [10]. A game of complete information is being played if the decision makers, in a conflict, are aware of how their opponent(s) would perceive the conflicting situation [11]. Each of the player, in a game, may perceive the game from her own point of view or information available to her. The players may not have complete information about the intentions of other players in a game. Since the courses of action(s) of a player, in a conflict, affect each other, so the misperception and/ or incomplete information may result in serious environmental catastrophe. It happened in Changzhou environmental conflict case. The misperception or incomplete information leads to hypergame. Hypergame analyses have been useful in modeling war and military issues [12 - 15], business [16], sports [17].

Furthermore, the hypergame analysis has also been useful modeling trade and E-commerce issues [18, 19], water resource conflicts [20] and bargaining and negotiations [21]. The literature on the application of the hypergame analysis reveals that there is no formal study on its application in modeling brownfield remediation conflicts. Since misperceptions, incomplete and asymmetric information about the nature and severity of pollutions in a brownfield may result in an adverse environmental catastrophe [4]. So, hypergame modeling would be useful in understanding the brownfield remediation conflicts and in providing appropriate and feasible solutions to specific brownfield conflicts.

The evolution of the Changzhou environmental conflict has two phases (Fig. 1). The local government, in the first phase of transition of the conflict, is deemed to have complete information about the severity of the noxious contamination and its consequences. The fact of incomplete remediation of the contaminated soil was known to the local government. But, on the other hand, the public believed it had been remediated completely. The public, due to asymmetric information about the pollution problem, did not appeal for the complete removal of the polluted soil (Fig. 1). So, this situation resulted in environmental catastrophe as about 500 students of the CFLS were reported to be adversely suffering from the severe diseases believed to be sourced from hazardous and perilous contamination next to the school. But, in the second level of the environmental conflict, the facts about the noxious pollution, incomplete remediation and its consequences were known to the public. So, the public outraged and demonstrated on the streets of Changzhou city. The public demanded for the complete removal of the contaminations and rehabilitation of the environment in the area (Fig. 1). Application of conflict analysis tools to examine an environmental conflict may not only provide a profound insight into the matter but also specify the avenues for the solution of the conflict. 


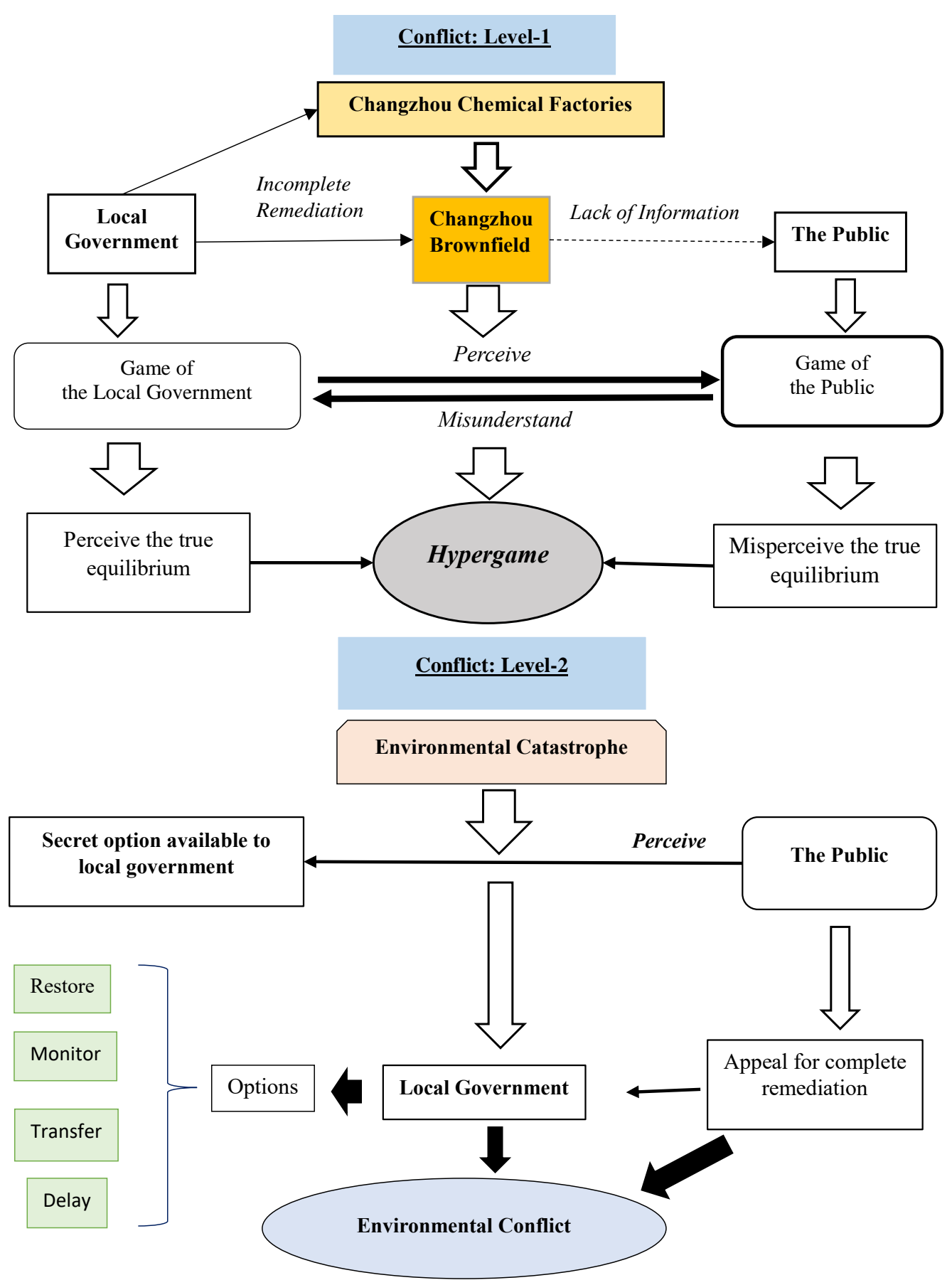

Fig. (1). The hybrid game for Changzhou environmental conflict.

The present study models an environmental conflict related to brownfield in Changzhou city, China, by using a hybrid game model. The conflict analysis, in this study, scrutinizes the evolution of the environmental issue and its possible solutions by using hypergame approach based on the GMCR [9]. Since the public, in the first level of the conflict, had the incomplete information about the situation so a hybrid game model is used to analyze the first phase of the conflict. The misperceptions or incomplete information can accurately be modeled as hypergames at different levels of a conflict $[22,23]$. In the latter phase, the stability and equilibrium conditions of the conflict are examined by using the GMCR. The present analysis of Changzhou brownfield conflict would provide a profound insight into the complex nature of the conflict and consequences of the asymmetric information available to the decision maker(s).

The rest of the paper is systematized as follows: section 2 comprises of the methodology used in the conflict analyses, section 3 represents a brief review of the evolution of the hypergame conflict, section 4 presents hybrid game 
model of Changzhou environmental conflict, section 5 comprises of the analysis of Changzhou brownfield conflict modeled by using the GMCR followed by the conclusion and policy implication in section 6 .

\section{BACKGROUND OF HYPERGAME IN THE GRAPH MODEL FOR CONFLICT ANALYSIS}

\subsection{Graph Model for Conflict Resolution}

\subsubsection{Definition 1 (GMCR):}

The graph model for conflict resolution (GMCR) is a 4-tuple $\left(N, S,\left(A_{i}\right)_{i \in N},\left(\succ_{i}, \sim_{i}\right)_{i \in N}\right.$, here $\mathrm{N}$ is the set of all DMs in a conflict $(|N| \geq 2)$, and $\mathrm{S}$ is the set of all states in a conflict $((|N| \geq 2))$. $\left(S, A_{i}\right)$ is $\mathrm{DM}_{i}$ 's graph, where $\mathrm{S}$ is the set of all vertices and $A_{i} \subset S \times S$ is set of all arcs such that $(s, s) \notin A_{i}$ for all $s \subset S$ and all $i \subset N$. The $\mathrm{DM}_{i}$ 's preference on $S$ are $\succ_{i}$ or $\sim_{i}$ If $\succ_{i}$ for $s, t \in S$, it implies that state $s$ is preferable to $t$ for $\mathrm{DM}_{i} \cdot s \sim_{i} t$ for $s, t \in S$, infers $\mathrm{DM}_{i}$ is indifferent between state $s$ and $t$. Moreover, $\succ_{i}$ is asymmetric for all $s, t \in S, s \succ_{i} t$ and $t \succ_{i} s$ cannot hold. $\forall s \in S, s \succ_{i} s, \sim_{i}$ is reflexive. $\sim_{i}$ is symmetric if $\forall s, t \in S, s \sim_{i} t$ or $t \sim_{i} s .\left(\succ_{i}, \sim_{i}\right)$ is complete if $\forall s, t \in S$, one of $s \succ_{i} t, t \succ_{i} s$ or $s \sim_{i} t$ holds [9].

\subsubsection{Definition 2 (UM and UI):}

The reachable list is record of all the states that a DM can unilaterally move (UM) to from a specific state in one step. The reachable list, for $i \in N$ and $s \in S$ for $\mathrm{DM}_{i}$ from $s$ symbolized by $R_{i}(s) \subset S$ is the set $\left\{t \in S \mid(s, t) \in A_{i}\right\}$. Unilateral Improvement (UI) for a DM is set of all states which she can move to from any initial state $s$ unilaterally. Emblematically, $\forall i \in N$ and $s, t \in S$ is the set $\left\{t \in R_{i}(s) \mid t \succ_{i} S\right\}$ and is specified as $R_{i}^{+}(s) \subset S$ [9].

Analysis is the basic step in a conflict study [10] but the analysis is based on some stability and solution concepts. A solution concept or stability definition illustrates how players interact given the strategy of their opponent(s). Stability of a given state is adjudged by specific stability definition(s). A state is deemed to be stable for a DM if it is not beneficial for her to move from that state. A state is in equilibrium if it is stable for all DMs in a conflict as per certain solution or stability concept $[9,24]$. The GMCR approach to conflict analysis $[9,25]$ and a range of stability definitions such as Nash stability [26], general metarationality (GMR) [27], Symmetric Metarationality (SMR) [27], and sequential stability (SEQ) [24] have been used in the present study.

\subsection{Hypergame in the GMCR}

The players or decision makers, in any environmental conflict, may have different interests despite having same objective to be achieved. Game theoretic models are at service for the conflict analysis and its resolution. In gametheoretic models, generally, the decision makers are assumed to have full understanding of conflict having common knowledge of all the aspects of conflict. But decision makers seldom have complete information or access to information about a certain conflict $[22,23,28,29]$. Each player, in this case, may have her own acuity about a certain conflict situation. Hypergame theory for conflict analysis serves better and provides a rigorous insight for the solution of the game [29]. Hypergames provide a mathematical structure to model a conflict in which the players perceive a conflict differently. Moreover, it provides the stability analysis algorithm and/or solution concepts to trace out the feasible solution(s) to the game [22].

Hypergame analysis allows for unbalance game model containing different views of the game based on each decision maker's perception. The unbalanced game model considers each player perception and view about the conflict. The decision maker(s) may misunderstand the situation or unaware of the actual situation in the conflict. Hypergame theory was firstly presented by Bennett (1977) [28] who with Dando put this theory into the real-world application (the fall of France during World War II). The player, in a hypergame, may have misunderstanding about the preference, incorrect comprehension of the options available to other DMs, misunderstanding about the attitudes and coalition among DMs, unaware of all the players in a conflict or have any combination of above interpretations [22, 25, 28]. Application of the hypergame theory ranges from military, sports, cyber, business and resource allocation problems [29] to environmental conflicts.

\section{THE ENVIRONMENTAL CONFLICT IN CHANGZHOU FOREIGN LANGUAGE SCHOOL (CFLS)}

The history of chemical plant factories in Changzhou dates back to 1958. These chemical factories, Changlong Chemical pesticide plant, Jiangsu Huada Chemical plant and Changzhou universal chemical, at that time, were located 
next to village in Xinbei county, Changzhou city of the Jiangsu province in China [30]. As the Changzhou city extended and developed over time the factory area was encircled by the city. The government, in 2009, decided to shift the chemical factories to new site. The former factory area was left as a brownfield as the chemical factories kept on dumping untreated noxious chemical waste in the factory cite area of about 266,700 square meters [5]. An independent survey, in 2012, unfolded the fact that there were precarious levels of toxic substances both in soil and ground water. Even though the soil was excavated but it still had its adverse impacts in that area. The brownfield area was treated and modified partially. Changzhou local government, for the use of abandoned industrial land, launched a remediation project for the restoration of soil and groundwater in the Changzhou brownfield area. The remediation project was supposed to be completed in April 2015 but the project was executed incompletely. The local government allowed the CFLS to be shifted next to the brownfield. The school became operational before the proper treatment of contaminated soil and water [31]. The school administration went ahead with the repositioning of the school to the new campus by overlooking the environmental repercussions [32].

Since the public was unaware of severity of the contaminations near the school so there was no serious appeal by the public for the proper and complete remediation or the restoration of the environment of the contaminated area. Though the Changzhou local government was cognizant of the contaminations. The plan to fully remove the contaminations was launched but it was not executed properly. Despite incomplete convalescence of the pollution the school was permitted to be relocated to the new campus [30]. In this transition state of the environmental conflict it is the case of hypergame as the upper panel of the Fig. (1) portrays the transition of the first phase (hypergame) of the Changzhou conflict.

Soon after the opening of school, in September 2015, parents and students noticed rotten-egg like smell in the area. The cases of complaints of strange smells, nose-bleeds, headache, cough and rashes were appeared [6]. Moreover, there were some serious health problems like cramps and skin disorders. The chemical factories dumped and buried chemical waste in 266,700 square meter area [5]. The parents urged the investigation of the matter by administration and the local government. The school was closed for two weeks, in January 2016, and city and provincial environmental authorities conducted investigations to consider the matter. The experts found elevated levels of contaminants but the officials asserted that the situation was not so serious. The second level of conflict starts with the documentary telecasted by the CCTV. On April 16, 2016, China's version of the Love lake the worst environmental catastrophe in the United States came into limelight with the report of CCTV $[5,7,8]$. It was reported that 493 out of 641 students of the CFLS, in physical examinations, were diagnosed with the ailments such as dermatitis, bronchitis, lymphoma and leukemia. It was also divulged that the school was shifted to a new 153-acre campus of CFLS closer to the chemical, pesticide and fertilizer factories' site in fall 2015.

Some alarming levels of toxic substances, in Changzhou brownfield area, were reported by the CCTV. Chlorobenzene levels in soil and groundwater were found to be 78,899 and 94,799 times, respectively, higher than that of admissible levels. Moreover, carbon tetrachloride levels were 22,699 times higher than that of national bounds. It was also unveiled that the perils were known to the government officials but school was granted with the permission to be relocated in the area. A third-party probes and scrutiny of the sight confirmed the soil to be contaminated with heavy metals such as chromium, iron and arsenic. The air was found to be contaminated with some pernicious organic contaminants such as benzene, toluene, acetone and dichloromethane. The quantity of chlorobenzene and carbon tetrachloride, in soil and water, were found to be tens of thousands time higher than the that of national levels. The elevated levels of noxious chemicals including chlorobenzene, a highly toxic solvent, damages liver, kidney and nervous system [5]. Higher concentrations of pollutants and chemicals might have caused diseases such as lymphoma and leukemia amongst the students [32].

Since the environmental contaminations were believed to be the original cause of the unprecedented catastrophic outbreak of diseases in the school students so the parents of the students showed their apprehensions about the health of their children and condemned the abrupt environmental incident. The public demonstrated and demanded the impartial investigation and complete remediation of the brownfield. The public of Changzhou city, in this case, demonstrated and appealed the government to resolve the pollution issue. The public, in this phase of the conflict, has the complete information about the environmental contamination and its consequences. Furthermore, the Changzhou local government has options whether to modify the contaminated land completely or modify it partially. But the public do not want to compromise on the issue since they have serious concerns about the health of their children. So, it is purely an environmental conflict and it is modeled and analyzed by using the most appropriate technique to conflict analysis, that is, GMCR $[9,25]$. 


\section{MODELING THE ENVIRONMENTAL CONFLICT IN CHANGZHOU FOREIGN LANGUAGE SCHOOL AS A HYBRID GAME}

\subsection{The Structure of Hypbrid Game for the Changzhou Conflict}

The buried chemical waste was not treated and environment was not restored appropriately. But the public was not aware of the severity of the pollution problem. The public perceived it as there were no serious pollution problem near the school. But soon after the start of the school, in fall 2015, the buried chemical industrial waste showed its adverse and hazardous impacts on the health of the students of the school. In this case the, public did not perceive the options available to the local government. The local government had two options either to restore the contaminated land completely or modify it partially. The latter option was not perceived by the public. The public perceived that the pollution problem had been fully resolved. Since the public was not aware of the option available to local government to partially modify the contamination so the Changzhou pollution conflict is a hypergame case. The public appeals for the modification of the area. But the government has another option to partially modify the polluted area. The latter option of the government is not perceived by the public. So, there becomes a case of lack of information of opponent decision maker's choices or actions. This conflict has a strategic surprise hypergame, because the public don't know the local government has a secret option not fully restore environment.

Since, in the first stage of the conflict, the public was unware of the severity of the contamination and its consequences so the public had lack of information about the pollution problem in Changzhou. This lack of information to one of the player in the conflict encourage us to use hypergame technique of conflict analysis to scrutinize the stability and equilibrium conditions in the conflict. Environmental conflicts can be modeled by using the tools of game theory [28, 33]. But, in this issue, the public, in the first stage, is not aware of government's second option so it is the case of hypergame. So, at the first level of the conflict, hybrid game model has been used to analyze the conflict. As incomplete information, can be modeled as hypergame as different level of conflict [22, 23]. So, in the present study, a hybrid game model has been developed by modeling the incomplete information available to DM2 as a hypergame at first level of the conflict and then analyze it using the GMCR [9] approach to conflict resolution.

\subsection{Decision Makers, Options and Feasible States at the First Level}

After the comprehensive review of the CFLS pollution conflict, there are two main players in the conflict; the local government (DM1) and the public (DM2). In the first stage of the conflict, the public had the option to appeal for the removal of the contamination and restoration of the environmental quality in the Changzhou brownfield (Table 1). The local government had two options to fully restore the environmental quality or modify it partially. The latter option was not perceived by the public (DM2).

Table 1. Options of decision makers at first level (hybrid game).

\begin{tabular}{|c|c|c|}
\hline Decision Makers & & Options \\
\hline \multirow[t]{2}{*}{$\begin{array}{l}\text { Local Government } \\
\quad \text { (DM1) }\end{array}$} & 1. Restore Environment & $\begin{array}{l}\text { The local government has the option to fully remediate and completely restore the } \\
\text { environment of the area }\end{array}$ \\
\hline & $\begin{array}{l}\text { 2. Restore a portion of } \\
\text { Environment (Secret) }\end{array}$ & $\begin{array}{l}\text { The local government also has the option to restore the environment partially but it is not } \\
\text { perceived by the public }\end{array}$ \\
\hline The Public (DM2) & 3. Appeal & $\begin{array}{l}\text { The public can appeal for this pollution event to environmental agency or superior } \\
\text { organization. }\end{array}$ \\
\hline
\end{tabular}

There would be 8 mathematical states, in the hypergame conflict model, with two decision makers and three options available to these decision makers. But the feasible states are 6 (Table 2). Since the third option was not perceived by the public so the public was not aware of the state 5 and 6 .

Table 2. Feasible states at first level (hybrid game).

\begin{tabular}{|c|c|c|c|c|c|c|c|}
\hline DMS & Options & \multicolumn{6}{|c|}{ Feasible states } \\
\hline \multirow{2}{*}{ Local government } & 1. Restore environment & $\mathrm{N}$ & $\mathrm{Y}$ & $\mathrm{N}$ & $\mathrm{Y}$ & $\mathrm{N}$ & $\mathrm{N}$ \\
\hline & 2. Restore a portion of environment (secret) & $\mathrm{N}$ & $\mathrm{N}$ & $\mathrm{N}$ & $\mathrm{N}$ & $\bar{Y}$ & $\mathrm{Y}$ \\
\hline Public & 3. Appeal & $\mathrm{N}$ & $\mathrm{N}$ & $\mathrm{Y}$ & $\mathrm{Y}$ & $\mathrm{N}$ & $\mathrm{Y}$ \\
\hline & Label & $\mathrm{S} 1$ & $\mathrm{~S} 2$ & S3 & S4 & $\mathrm{S} 5 *$ & S6* \\
\hline
\end{tabular}




\subsection{Reachable List at the First Level (Hybrid Game)}

The reachable list of each of the DM in the conflict is given in Table 3. Here, $R_{P}(s)$ denotes the reachable set of the public; $R_{L P}(s)$ symbolizes the reachable set of the local government perceived by public; $R_{L}(s)$ represents the actual reachable set of local government. The reachable list from state 1-4 is known to public but the reachable list from state $5^{*}$ and $6^{*}$ are not known to public. Since the public could not perceive the second option available to the LG so the public was unaware of the $R_{L}\left(5^{*}\right) \subset\{1,2\}$ and $R_{L}\left(6^{*}\right) \subset\{3,4\}$.

Table 3. Reachable states at the first level (hybrid game).

\begin{tabular}{|c|c|c|c|}
\hline States & $\mathbf{R}_{L}(\mathbf{s})$ & $\mathbf{R}_{P}(\mathbf{s})$ & $\mathbf{R}_{L P}(\mathbf{s})$ \\
\hline $\mathrm{S} 1$ & $\mathrm{~S} 2, \mathrm{~S} 5$ & $\mathrm{~S} 3$ & $\mathrm{~S} 2$ \\
\hline $\mathrm{S} 2$ & $\mathrm{~S} 1, \mathrm{~S} 5$ & $\mathrm{~S} 4$ & $\mathrm{~S} 1$ \\
\hline $\mathrm{S} 3$ & $\mathrm{~S} 4, \mathrm{~S} 6$ & $\mathrm{~S} 1$ & $\mathrm{~S} 3$ \\
\hline $\mathrm{S} 4$ & $\mathrm{~S} 3, \mathrm{~S} 6$ & $\mathrm{~S} 2$ & unaware \\
\hline $\mathrm{S} 5 *$ & $\mathrm{~S} 1, \mathrm{~S} 2$ & unaware & unaware \\
\hline $\mathrm{S} 6 *$ & $\mathrm{~S} 3, \mathrm{~S} 4$ & unaware \\
\hline
\end{tabular}

\subsection{Preferences in the First Level of the Conflict}

The preference statements of the players (Table 4) divulges that the most favorite option for the public is the complete removal of contaminations and full restoration of the environment in the area by the local government. The public would choose not to appeal for if the LG addresses the pollution problem by resolving the issue appropriately. The least preferred option for the public is to appeal and demonstrate if the local government does not resolve the pollution problem. The preferred option for local government is not appeal by the public; the second is not restore environment. The last is not to restore a portion of environment.

Table 4. Preference statements at first level (hybrid game).

\begin{tabular}{|l|c|c|}
\hline $\mathbf{L}_{\mathbf{L}}$ & $\mathbf{L}_{\mathbf{P}}$ & $\mathbf{L}_{\mathbf{L} \mathbf{P}}$ \\
\hline-1 & 2 & -1 \\
-2 & $-1 \| 2$ & -2 \\
-3 & $1 \|-2$ & \\
\hline \multicolumn{2}{|c|}{$L_{L}=$ the option statement of actual options of local government. } \\
\multicolumn{2}{|c|}{$L_{P}=$ Option statement of public } \\
\multicolumn{2}{|c|}{$L_{L P}=$ Option statements of local government perceived by public } \\
\hline
\end{tabular}

The option statements in the Table $\mathbf{4}$ yields to the preference of statements summarized in Table 5. Referring to the preferences of the public the state 2 is the most favorable state to the public. The state 2 (YNN) means the public would not appeal if the contaminations and pollution is removed by the local government. The state 1 is the least preferred stat to the public but it is the most preferable state for the local government as perceived by the public. This state (NNN) implies that government does not want to address the pollution problem in the area and the public should not appeal or demonstrate. The actual preferred state for the local government is also 1 but the overall preference is $\mathrm{S} 1>\mathrm{S} 5^{*}>\mathrm{S} 2>$ S3 $>$ S6* $>$ S4. This preference affects the movement from the moves and countermoves during the negotiations of the conflict affecting the possible solutions of the conflict.

Table 5. Preferences at first level (hybrid game).

\begin{tabular}{|c|c|}
\hline Local government (actual) & $\mathrm{S} 1>\mathrm{S} 55^{*}>\mathrm{S} 2>\mathrm{S} 3>\mathrm{S} 6^{*}>\mathrm{S} 4$ \\
\hline Public & $\mathrm{S} 2>\mathrm{S} 4>\mathrm{S} 3>\mathrm{S} 1$ \\
\hline Local government perceived by Public & $\mathrm{S} 1>\mathrm{S} 2>\mathrm{S} 3>\mathrm{S} 4$ \\
\hline
\end{tabular}

\subsection{Stability Analysis at the First Level (Hybrid Game)}

The results of the stability analyses based on the preference vector Table $\mathbf{5}$ is summarized in Table $\mathbf{6}$. The public has the UI from state 1 to 3 so the state 1 is unstable $(\mathrm{u})$. The state 2 and 3 are Nash stable $(\mathrm{r})$ as $\mathrm{R}_{\mathrm{P}}^{+}(2)=\phi$ and $\mathrm{R}_{\mathrm{P}}^{+}(3)$. Whereas, state 4 is SEQ stable (s) as with the movement of the public from state 4 to 2 can be sanctioned by the local government (as perceived by the public) if LG move from state 2 to 1 since $2 \succ_{P} 1$. As far as the local government is concerned the state 1 and 3 are Nash stable as $\mathrm{R}_{\mathrm{L}}^{+}(1)=\phi$ and $\mathrm{R}_{\mathrm{L}}^{+}(3)=\phi$ and this is the most preferred state for the $\mathrm{LG}$. 
Table 6. Stability analysis at first level of conflict (hybrid game).

\begin{tabular}{|c|c|c|c|c|c|c|c|c|c|c|c|c|c|c|}
\hline \multirow[t]{2}{*}{ States } & \multicolumn{3}{|c|}{ NASH } & \multicolumn{3}{|c|}{ GMR } & \multicolumn{3}{|c|}{ SMR } & \multicolumn{3}{|c|}{ SEQ } & \multicolumn{2}{|c|}{$\mathbf{E}$} \\
\hline & $\mathbf{L}$ & $\mathbf{P}$ & $\mathbf{L}_{\mathbf{P}}$ & $\mathbf{L}$ & $\mathbf{P}$ & $\mathbf{L}_{\mathrm{P}}$ & $\mathbf{L}$ & $\mathbf{P}$ & $\mathbf{L}_{\mathrm{P}}$ & $\mathbf{L}$ & $\mathbf{P}$ & $\mathbf{L}_{\mathrm{P}}$ & & \\
\hline S1 & $\sqrt{ }$ & & $\sqrt{ }$ & $\sqrt{ }$ & & $\sqrt{ }$ & $\sqrt{ }$ & & $\sqrt{ }$ & $\sqrt{ }$ & & $\sqrt{ }$ & $*$ & \\
\hline S2 & & $\sqrt{ }$ & & & $\sqrt{ }$ & $\sqrt{ }$ & & $\sqrt{ }$ & $\sqrt{ }$ & & $\sqrt{ }$ & $\sqrt{ }$ & & * \\
\hline S3 & $\sqrt{ }$ & $\sqrt{ }$ & $\sqrt{ }$ & $\sqrt{ }$ & $\sqrt{ }$ & $\sqrt{ }$ & $\sqrt{ }$ & $\sqrt{ }$ & $\sqrt{ }$ & $\sqrt{ }$ & $\sqrt{ }$ & $\sqrt{ }$ & & * \\
\hline S4 & & & & & $\sqrt{ }$ & & & $\sqrt{ }$ & & & $\sqrt{ }$ & & & \\
\hline S5* & & $\sqrt{ }$ & & $\sqrt{ }$ & $\sqrt{ }$ & & $\sqrt{ }$ & $\sqrt{ }$ & & $\sqrt{ }$ & $\sqrt{ }$ & & $*$ & \\
\hline S6* & & $\sqrt{ }$ & & & $\sqrt{ }$ & & & $\sqrt{ }$ & & & $\sqrt{ }$ & & & \\
\hline
\end{tabular}

The state 2 is SEQ stable for the LG as if public perceived its movement from 2 to 1 but public can move to 3 which is less preferable for the LG. The public is unaware of the state 5 and 6 . In this situation the state 1 and 3 are still Nash stable for the LG. So, the results of the hypergame analysis are evident that the public perceived the state 2 and 3 as equilibrium. The state 2 means the public does not appeal for the restoration of the environment and the LG removes the contaminations. The state 3 and 5 are true equilibrium perceived by local government, because local government knew the game of public but public is not aware of the option of incomplete remediation. The state $5^{*}$ is an actual equilibrium perceived by local government.

In the state $5^{*}$ the public could not perceive the partial remediation of brownfield by the LG so government did not appeal. Though the state $5^{*}$ is an equilibrium in the hypergame conflict but it has its consequences. There were hazardous chemical contaminations in the brownfield but the area was remediated partially. The public remained unaware of the problem. The hazardous contaminations showed its adverse impacts on the environmental and the students of the CFLS suffered adversely. The CCTV report unveiled the truth and aired that about 500 students of CFLS as discussed in section 2. The public and the parents of the students were outraged. There were demonstrations and strike in the Changzhou city. The public showed their concern over the Changzhou brownfield issue all over the country and demanded the government to address the issue. So, when the public realized that the chemical and industrial contaminations were not removed and chemical waste was not removed properly the public started appealing for the restoration of the environment. Though the state 3 was an equilibrium for both decision makers but it was not stable anymore after the telecast of CCTV report.

\section{MODELING THE ENVIRONMENTAL CONFLICT IN CHANGZHOU FOREIGN LANGUAGE SCHOOL AS A GAME}

Since the public, in the first level of the CFLS conflict, was unaware of the contaminations in the Changzhou brownfield and the local government paid no heed to remove the pollutions completely it resulted in environmental catastrophe. Now the public is aware of the options available to the local government. Extreme environmental contamination near the foreign language school in Changzhou got much more attention of the public, environmentalists, electronic and print media, social media and the government as well. In the second stage of the conflict, after the outbreak of the CCTV report, the scenario change. This environmental issue has become a big challenge for the local government and environmental friendly organizations. As the soil and underground water contamination has been reported to show its adverse and alarming impacts of the health of the students of the school. So, it is a conflict warranting its immediate solution.

The public of Changzhou city appeal the government for the modification of the polluted land so that there may be no health risks to their children in the school and the people living in the surroundings of the polluted land. So, in the second level of the conflict, attempt is to construct a model based on the GMCR. The GMCR is a very suitable and powerful analytical technique for conflict resolution analysis $[21,25]$. The stability analysis has been carried out by using NUAAGMCR software.

\subsection{The Decision Makers, Options and Feasible States at Second Level}

The CFLS conflict has been modeled by using the GMCR [9]. The key decision makers, in this conflict, are the parents of the students, civil society, public and the environmentalists but these stakeholders are merged into one decision maker; the Public. The other main decision maker is the local government. Five options, in the CFLS conflict, 
are available to both decision makers (Table 7). The local government (DM1) has the four options available to her. Firstly, the local government has the option to restore the environmental quality of the industrial site or not. Second option is to monitor and enforce (Monitor) the health checkups of students and share the results of these checkups the public periodically. Thirdly, DM1 has the option to shift the school to a new place temporarily until the resolution of the environmental improvement. Fourthly, it has the option to delay the issue. The public (DM1) has the one option

available; Appeal. The public can appeal the local government and environmental agencies or superior authorities to resolve the environmental issue.

Table 7. Decision makers and options at second level.

\begin{tabular}{|c|c|c|}
\hline Decision Makers & \multicolumn{2}{|c|}{ Options } \\
\hline $\begin{array}{c}\text { Local Government } \\
\text { (DM1) }\end{array}$ & 1. Restore & Local government can restore the polluted land or not. \\
\cline { 2 - 3 } & 2. Monitor & $\begin{array}{c}\text { Local government can take measures to enforce the health checkup of students and periodically share the result of } \\
\text { environmental monitoring with the public. }\end{array}$ \\
\cline { 2 - 3 } & 3. Transfer & Local government can choose to transfer the students and teachers to a new place temporarily. \\
\cline { 2 - 3 } & 4. Delay & Local government can delay this issue. \\
\hline The Public (DM2) & 5. Appeal & The public can appeal for this pollution event to environmental agency or superior organization. \\
\hline
\end{tabular}

Next stage is to identify the feasible states in the model. Since there are two decision makers, in the conflict, having 5 options so there maybe 32 possible mathematical states. However, some states are infeasible, such as NNYYN. Because local government cannot choose to transfer if it selects to delay. The number of feasible states is only 12 (Table 8) and Fig. (2) much less than the mathematical states. The infeasible states are removed by using NUAAGMCR.

Table 8. Feasible states at second level.

\begin{tabular}{|c|c|c|c|c|c|c|c|c|c|c|c|c|c|}
\hline DMs & Options & $\boldsymbol{s}_{\mathbf{1}}$ & $\boldsymbol{s}_{\mathbf{2}}$ & $\boldsymbol{s}_{\mathbf{3}}$ & $\boldsymbol{s}_{\mathbf{4}}$ & $\boldsymbol{s}_{\mathbf{5}}$ & $\boldsymbol{s}_{\mathbf{6}}$ & $\boldsymbol{s}_{\mathbf{7}}$ & $\boldsymbol{s}_{\mathbf{8}}$ & $\boldsymbol{s}_{\mathbf{9}}$ & $\boldsymbol{s}_{\mathbf{1 0}}$ & $\boldsymbol{s}_{\mathbf{1 1}}$ & $\boldsymbol{s}_{\mathbf{1 2}}$ \\
\hline $\mathrm{LG}$ & 1. Restore & $\mathrm{N}$ & $\mathrm{N}$ & $\mathrm{N}$ & $\mathrm{N}$ & $\mathrm{N}$ & $\mathrm{N}$ & $\mathrm{Y}$ & $\mathrm{Y}$ & $\mathbf{Y}$ & $\mathrm{Y}$ & $\mathbf{Y}$ & $\mathrm{Y}$ \\
\hline & 2. Monitor & $\mathrm{N}$ & $\mathrm{N}$ & $\mathrm{N}$ & $\mathrm{N}$ & $\mathrm{Y}$ & $\mathrm{Y}$ & $\mathrm{N}$ & $\mathrm{N}$ & $\mathbf{N}$ & $\mathrm{N}$ & $\mathbf{Y}$ & $\mathrm{Y}$ \\
\hline & 3. Transfer & $\mathrm{N}$ & $\mathrm{N}$ & $\mathrm{Y}$ & $\mathrm{Y}$ & $\mathrm{N}$ & $\mathrm{N}$ & $\mathrm{N}$ & $\mathrm{N}$ & $\mathbf{Y}$ & $\mathrm{Y}$ & $\mathbf{N}$ & $\mathrm{N}$ \\
\hline Public & 4. Delay & $\mathrm{Y}$ & $\mathrm{Y}$ & $\mathrm{N}$ & $\mathrm{N}$ & $\mathrm{N}$ & $\mathrm{N}$ & $\mathrm{Y}$ & $\mathrm{Y}$ & $\mathbf{N}$ & $\mathrm{N}$ & $\mathbf{N}$ & $\mathrm{N}$ \\
\hline
\end{tabular}

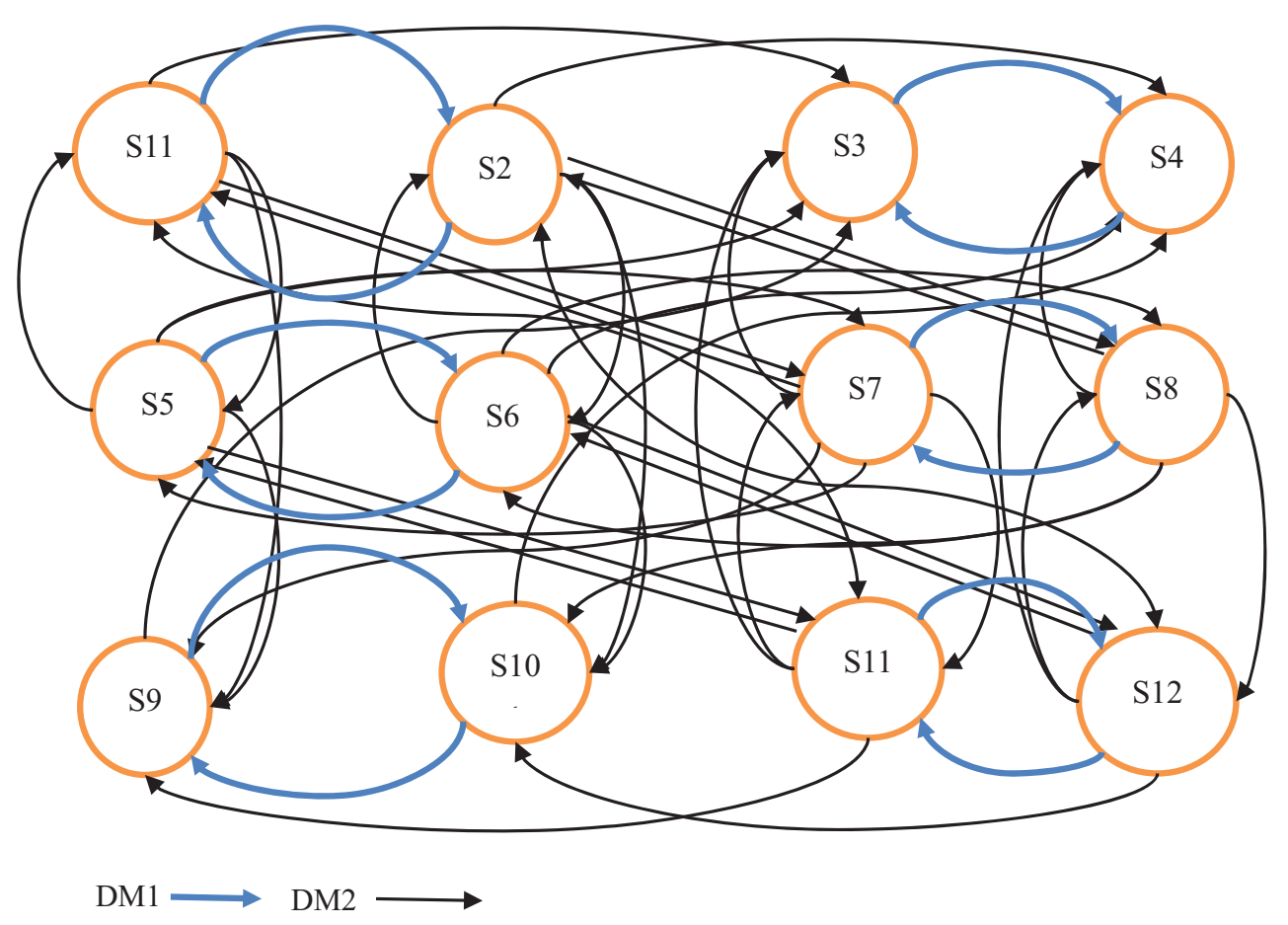

Fig. (2). State transition graph at second level. 


\subsection{Preference Statements at Second Level}

Here, we use the method of option prioritization to obtain the preferences of DMs. The preference statements of DMs are listed in Table 9. The most preferred option for the government is to modify the contaminated land. It is preferred to monitoring measures and transfer of students and teachers temporarily to some other place. The least preferred option for the local government (LG) is delaying the issue. The public appeal and demonstration is the unfavorable option for the local government. The preference of the options for DM1 results in the ordered state preference given in the second last row of Table 9. The most preferred state for the local government is state 11. The state 11 (YYNNN) means that local government prefers the modification of the contaminations and restore the environment and monitor the enforcement of periodical medical checkup and share with the public but the public needs not to appeal during the process. The state 4 (NNYNY) is the least preferred state for the local government.

Table 9. Option statements of DMs at second level.

\begin{tabular}{|c|c|c|}
\hline DMs & Statements & Explanation \\
\hline \multirow{5}{*}{ LG (DM1) } & -5 & LG wishes the public not to appeal for \\
\hline & 1 & LG wants to restore the polluted land \\
\hline & 2 & LG wants to take monitoring measures \\
\hline & 4 & LG wants to delay this issue \\
\hline & 3 & LG wants to transfer the students and teachers \\
\hline \multirow{5}{*}{$\begin{array}{l}\text { Public (DM2) } \\
\text { (DM2) }\end{array}$} & 3 & Public wants LG to transfer the students and teachers \\
\hline & -4 & Public does not want LG to delay \\
\hline & 1 & Public wants LG to restore the land pollution \\
\hline & 2 & Public wants LG to taker monitoring measures \\
\hline & 5IFF4 & Public will not appeal for if and only if LG chooses to delay this issue \\
\hline DM1 & & $\left(s_{11}>_{s_{7}}>_{s_{9}}>_{s_{5}}>_{s_{1}}>_{s_{3}}>_{s_{12}}>_{s_{8}}>_{s_{10}}>_{s_{6}}>_{s_{2}}>_{s_{4}}\right)$ \\
\hline DM2 & & $\left(s_{9}>_{s_{10}}>_{s_{3}}>_{s_{4}}>_{s_{11}}>_{s_{12}}>{ }_{s_{5}}>_{s_{6}}>_{s_{8}}>_{s_{7}}>_{s_{2}}>{ }_{s_{1}}\right)$ \\
\hline
\end{tabular}

Modification of the contaminated land and restoration of the environment is also the most preferred option for the public. It is preferred to monitoring and transfer of the school temporarily. The public would keep on appealing if the LG chose to delay the issue. The most unfavorable option for the public is the delay by the LG to resolve the issue. These option preferences yield in state preferences $\left(s_{9}>s_{10}>s_{3}>s_{4}>s_{11}>s_{12}>s_{5}>s_{6}>s_{8}>s_{7}>s_{2}>s_{1}\right)$ for the public (DM2). The state 9 (YNYNN) implies that most preferred strategy for the public is not to appeal if the LG restores the environment by modifying the pollution and shift the school to new place temporarily without any delay. The state 1 (NNNYN) is the least preferred state for the public.

\subsection{Stability Analysis Results at Second Level}

The stability results of the conflict (given in Table 10), based the Nash, GMR, SMR, and SEQ stability definitions have been obtained by using the NUAAGMCR software. In the stability results table, a check $(\sqrt{ })$ indicates that the state is stable for the DM under corresponding solution concept. The asterisk (*) shows that the respective state is an equilibrium under a certain stability definition for both DMs in the game. The equilibrium of the game is referred to the state which is stable for both DMs under a certain stability definition(s) [9, 34]. The state 12 is only Nash stable for $\mathrm{DM} 1$ as $\mathrm{R}_{1}^{+}(12)=\phi$. Whereas, the states $2,3,5$ and 8 are Nash stable for DM2 since $\mathrm{R}_{2}^{+}(2)=\phi, \mathrm{R}_{2}^{+}(3)=\phi, \mathrm{R}_{2}^{+}(5)=\phi$ and $\mathrm{R}_{2}^{+}(8)=\phi$ respectively given the decision of $\mathrm{DM}_{1}$. The states 3, 5, 7 and 12 are GMR for both DMs. Referring to the state 3, f DM1 decides to transfer the school rather to modify the contaminated land and monitor the measures to enforce the health checkup of students and periodically share the result of environmental monitoring with the public (DM2) can move to state 1 or 5 so 3 is GMR for DM1. The GMR stability of the other states can be verified. 3, 5, 7, 10 and 12 are SMR for all the DMs in the conflict. The state 3 is SMR for both DMs since DM1 cannot escape the sanction enforced by DM2. Similarly, DM2 is also unable to avoid the sanction enforced by her opponent. The SMR stability for the other states is also verifiable (Table 10).

Table 10. Stability results of Changzhou school pollution conflict.

\begin{tabular}{|c|c|c|c|c|c|c|c|c|c|c|c|c|}
\hline \multirow{2}{*}{ States } & \multicolumn{3}{|c|}{ Nash } & \multicolumn{3}{|c|}{ GMR } & \multicolumn{3}{|c|}{ SMR } & \multicolumn{3}{|c|}{ SEQ } \\
\hline & DM1 & DM2 & $\mathbf{E}$ & DM1 & DM2 & $\mathbf{E}$ & DM1 & DM2 & $\mathbf{E}$ & DM1 & DM2 & $\mathbf{E}$ \\
\hline$s_{1}$ & & & & $\sqrt{ }$ & & & $\sqrt{ }$ & & & & & \\
\hline
\end{tabular}


(Table 1ロ) contd....

\begin{tabular}{|c|c|c|c|c|c|c|c|c|c|c|c|c|}
\hline \multirow{2}{*}{ States } & \multicolumn{3}{|c|}{ Nash } & \multicolumn{3}{|c|}{ GMR } & \multicolumn{3}{|c|}{ SMR } & \multicolumn{3}{|c|}{ SEQ } \\
\hline & DM1 & DM2 & $\mathbf{E}$ & DM1 & DM2 & $\mathbf{E}$ & DM1 & DM2 & $\mathbf{E}$ & DM1 & DM2 & $\mathbf{E}$ \\
\hline$s_{2}$ & & $\sqrt{ }$ & & & $\sqrt{ }$ & & & $\sqrt{ }$ & & & $\sqrt{ }$ & \\
\hline$S_{3}$ & & $\sqrt{ }$ & & $\sqrt{ }$ & $\sqrt{ }$ & $*$ & $\sqrt{ }$ & $\sqrt{ }$ & $*$ & & $\sqrt{ }$ & \\
\hline$s_{4}$ & & & & & & & & & & & & \\
\hline$S_{5}$ & & $\sqrt{ }$ & & $\sqrt{ }$ & $\sqrt{ }$ & $*$ & $\sqrt{ }$ & $\sqrt{ }$ & $*$ & & $\sqrt{ }$ & \\
\hline$s_{6}$ & & & & & $\sqrt{ }$ & & & $\sqrt{ }$ & & & $\sqrt{ }$ & \\
\hline$s_{7}$ & & & & $\sqrt{ }$ & $\sqrt{ }$ & $*$ & $\sqrt{ }$ & $\sqrt{ }$ & $*$ & & & \\
\hline$s_{8}$ & & $\sqrt{ }$ & & & $\sqrt{ }$ & & & $\sqrt{ }$ & & & $\sqrt{ }$ & \\
\hline$S_{9}$ & $\overline{\sqrt{ }}$ & $\sqrt{ }$ & $*$ & $\sqrt{ }$ & $\sqrt{ }$ & $*$ & $\overline{\sqrt{ }}$ & $\sqrt{ }$ & $*$ & $\overline{\sqrt{ }}$ & $\overline{\sqrt{ }}$ & * \\
\hline$s_{10}$ & $\sqrt{ }$ & & & $\sqrt{ }$ & $\sqrt{ }$ & $*$ & $\sqrt{ }$ & $\sqrt{ }$ & $*$ & $\sqrt{ }$ & & \\
\hline$s_{11}$ & $\sqrt{ }$ & $\sqrt{ }$ & $*$ & $\sqrt{ }$ & $\sqrt{ }$ & $*$ & $\sqrt{ }$ & $\sqrt{ }$ & $*$ & $\sqrt{ }$ & $\sqrt{ }$ & * \\
\hline$s_{12}$ & $\sqrt{ }$ & & & $\sqrt{ }$ & $\sqrt{ }$ & $*$ & $\sqrt{ }$ & $\sqrt{ }$ & $*$ & $\sqrt{ }$ & & \\
\hline
\end{tabular}

The state 9 and 11 are Nash, GMR, SMR and SEQ for both decision makers in the present modelled environmental conflict. Since $\mathrm{R}_{1}^{+}(9)=\phi$ and $\mathrm{R}_{2}^{+}(9)=\phi$ so the state 9 is Nash stable for both of DMs and it also Nash equilibrium for the DMs in the game. The state 9 specifies that the local government chooses to restore the polluted land and simultaneously transfer the students to a new place, in which the public choose not to appeal for. So, the state 9 is a satisfactory equilibrium in this conflict. The 11 is also Nash equilibrium as it is Nash stable for both decision makers as $\mathrm{R}_{1}^{+}(11)=\phi$ and $\mathrm{R}_{2}^{+}(11)=\phi$. The state 11 means that local government prefers to restore the land pollution and take measures to enforce the health checkup of students and periodically share the result of environmental monitoring with the public, which is consistent with the realistic solution. The state 11 is also Nash, GMR, SMR and SEQ for DM2 as per definitions. The equilibrium solutions $(9 \& 11)$ are stronger solutions and have higher chances to be the final solution of the CFLS environmental conflict as these equilibrium solutions are stable under variety of stable equilibrium definitions.

\section{CONCLUSION AND FUTURE WORKS}

In this present study, Changzhou school environmental conflict has been modeled to trace out stability and solution of the conflict by using hybrid game model. Environmental problems sourced from the human actions coupled with higher levels of economics growth need to be resolved. The objectives of the stakeholders while finding the solution of the environmental conflict may be same but they may differ in finding the way to solutions of the environmental conflicts. Information about the nature, severity and the consequences of the environmental contamination is very important. Asymmetric information about a certain environmental site results in environmental catastrophe as happened in Changzhou. Since the Changzhou pollution conflict has its two phases so its stability and solutions have been analyzed in two steps. In the first step, hypergame based on the GMCR (hybrid game) is employed to examine the conflict. Since the public was unaware of the fact so in the hyper-game model, the equilibrium states are state 2 and 3. In fact, the situation was different. The brownfield was not remediated properly. So, the equilibrium perceived by the LG comprised state 5 and 6 . Since the public did not have proper information or access to information about the true nature of the contaminations, so no appeal for proper removal of contamination by the public resulted in adverse impacts on students' health.

The failure to proper remediation of the brownfield and shifting of the school next to the brownfield resulted in health problem in about 500 students of the school. The public outraged and demanded the complete and proper convalescence of the area. Since, in this second phase of the conflict, the public is aware of the nature and severity of the contaminations in the area so the GMCR has been applied to scrutinize the stability and equilibrium under most suitable multiple stability and solution definitions. The analysis of the conflict revealed state 9 (YNYNN) and 11 (YYNNN) as equilibrium states. The state 9 means the LG restores the environment of the area by completely remediating the brownfield and in the meanwhile, the school is temporarily transferred to some other place. Whereas, the state 11 implies that the local government restores the environment and monitors to enforce the health checkup of students and periodically without shifting the school and share the result of environmental monitoring with the public.

The Changzhou environmental tragedy questions the implementation and monitoring of the environmental laws. It implies and warrants a stringent implementation mechanism and monitoring system. The legislation, environmental laws and implementation of these laws are devoid of accountability. There must be a proper system for the accountability of the concerned institutions and environmental agencies involved in the matter. Moreover, legislation 
and existing laws regarding current environmental scenario might be outdated. So, it calls for proper legislation to deal with the modern world environmental issues of complex nature. Furthermore, the use of suitable and viable technology for remediation has fundamental importance. An appropriate but feasible technology should be specified in an environmental convalescence plan. Since the remediation process, generally, is very costly so, in most of the cases, polluted topsoil is removed to reduce cost and time for remediation process but removed topsoil is land-filled somewhere else causing another environmental hazard. Incongruous remediation by removing only the topsoil would release buried contaminants resulting in environmental catastrophe. So, the appropriate and viable technology is required to achieve the objectives of remediation. Since environmental remediation and rehabilitation process is prone to high costs involved so it makes the finances and their resources indispensable source of concern. It calls for a comprehensive environmental financial policy to consider and involve the stakeholders through environmental tax and clean-up of subsidy mechanisms.

\section{CONFLICT OF INTEREST}

The authors confirm that this article content has no conflict of interest.

\section{ACKNOWLEDGEMENTS}

The authors appreciate financial support from the National Natural Science Foundation of China (71471087, 71071076, and 61673209).

\section{REFERENCES}

[1] K. Cao, and H. Guan, "Brownfield redevelopment toward sustainable urban land use in china", Chin. Geogr. Sci., vol. 17, no. 2, pp. 127-134, 2007.

[http://dx.doi.org/10.1007/s11769-007-0127-5]

[2] H. Meuser, "Rehabilitation of soils in urban environments", In: Soil Remediation and Rehabilitation., Springer Science: Netherlands, 2012, pp. 5-36. [http://dx.doi.org/10.1007/978-94-007-5751-6_2]

[3] L. Wang, L. Fang, and W. Keith, A game-theoretic approach to brownfield redevelopment: negotiation on cost and benefit allocation., 2007. Available at: http://www.hjxf.net/uploadfile/2012/0914/20120914111256520.pdf

[4] H. Yang, "China soil plan needs strong support", Nature, vol. 536, no. 7617, pp. 375-375, 2016. [http://dx.doi.org/10.1038/536375a] [PMID: 27558029]

[5] Z. Chun, Changzhou pollution scandal highlights holes in china's environmental enforcement, 2016. Available at: https://www.china dialogue.net/article/show/single/en/8892-Changzhou-pollution-scandal-highlights-holes-in-China-s-environmental-enforcement

[6] L. Hornby, Chinese environment: ground operation. In: Financial Times, 2016. Available at: https://www.ft.com/content/d096f594-4be011e5-b558-8a9722977189

[7] A. Mah, The US love canal disaster and its legacy, 2016. Available at: https://www.chinadialogue.net/article/show/single/en/8878 The $\neg$ US $\neg$ Love $\neg$ Canal $\neg$ disaster $\neg$ and $\neg$ its $\neg$ legacy

[8] T. Phillips, Another 'toxic school' case leads to closure of Chinese chemical works, 2016. Available at: https://www.theguardian.com/ world/2016/apr/22/another-toxic-school-case-leads-to-closure-of-chinese-chemical-works

[9] L. Fang, K.W. Hipel, and M.D. Kilgour, Interactive decision making: The graph model for conflict resolution in Amazon.com: Books., vol. 3. Wiley-Interscience: New York, 1993.

[10] K.W. Hipel, and S.B. Walker, "Conflict analysis in environmental management", Environmetrics, vol. 22, no. 3, pp. 279-293, 2010. [http://dx.doi.org/10.1002/env.1048]

[11] K.W. Hipel, M. Wang, and N.M. Fraser, "Hypergame analysis of the Falkland/Malvinas conflict", Int. Stud. Q., vol. 32, no. 3, p. 335, 1988. [http://dx.doi.org/10.2307/2600446]

[12] P.G. Bennett, and M.R. Dando, "Complex strategic analysis: A hypergame study of the Fall of France", J. Oper. Res. Soc., vol. 30, pp. 23-32, 1979.

[http://dx.doi.org/10.1057/jors.1979.3]

[13] A.K. Said, and D.A. Hartley, "A hypergame approach to crisis decision making. The 1973 Middle East war", J. Oper. Res. Soc., vol. 33, pp. 937-948, 1982. [http://dx.doi.org/10.1057/jors.1982.198]

[14] N.M. Fraser, K.W. Hipel, and J.R. del Monte, "Approaches to conflict modeling: a study of a possible USA-USSR nuclear confrontation", J. Policy Model, vol. 5, no. 3, pp. 397-417, 1983.

[http://dx.doi.org/10.1016/0161-8938(83)90005-4]

[15] M.A. Takahashi, N.M. Fraser, and K.W. Hipel, "A procedure for analyzing hypergames", Eur. J. Oper. Res., vol. 18, pp. 111-122, 1984. [http://dx.doi.org/10.1016/0377-2217(84)90268-6] 
[16] M. Giesen, and P.G. Bennett, "Aristotle's fallacy: A hypergame in the oil shipping business", Omega, vol. 7, pp. 309-320, 1979. [http://dx.doi.org/10.1016/0305-0483(79)90036-7]

[17] P.G. Bennett, M.R. Dando, and R.G. Sharp, "Using hypergames to model difficult social issues: An approach to the case of soccer hooliganism", J. Oper. Res. Soc., vol. 31, no. 7, pp. 621-635, 1980.

[http://dx.doi.org/10.1057/jors.1980.120]

[18] N.W. Stokes, and K.W. Hipel, "Conflict analysis of an export credit trade dispute", Omega, vol. 11, pp. 365-376, 1983. [http://dx.doi.org/10.1016/0305-0483(83)90029-4]

[19] L. Maxime, and B. Ghaib-draa, Hypergame Analysis in E-commerce: A preliminary report, Science Series., CIRANO, 2002.

[20] N. Okada, K.W. Hipel, and Y. Oka, "Hypergame analysis of the lake Biwa conflict", Water Resour. Res., vol. 21, pp. 917-926, 1985. [http://dx.doi.org/10.1029/WR021i007p00917]

[21] N.M. Fraser, K.W. Hipel, and J.R. del Monte, "Approaches to conflict modeling: A study of a possible USA-USSR nuclear confrontation", J. Policy Model., vol. 5, no. 3, pp. 397-417, 1983. [http://dx.doi.org/10.1016/0161-8938(83)90005-4]

[22] M. Wang, K.W. Hipel, and N.M. Fraser, "Modeling misperceptions in games", Behav. Sci., vol. 33, no. 3, pp. 207-223, 1988. [http://dx.doi.org/10.1002/bs.3830330305]

[23] Y. Sasaki, "Subjective Rationalizability in Hypergames", Adv. Decis. Sci., vol. 2014, pp. 1-7, 2014. [http://dx.doi.org/10.1155/2014/263615]

[24] N.M. Fraser, and K.W. Hipel, "Conflict analysis as a negotiation support system", In: B. Munier, and M. Shakun, Eds., Compromise, Negotiation and Group Decision., Springer Science: Netherlands, 1988, pp. 225-243. [http://dx.doi.org/10.1007/978-94-009-4021-5_15]

[25] D.M. Kilgour, and K.W. Hipel, "Conflict analysis methods: The graph model for conflict resolution", In: Advances in Group Decision and Negotiation., Springer Science: Netherlands, 2010, pp. 203-222. [http://dx.doi.org/10.1007/978-90-481-9097-3_13]

[26] J. Nash, "Non-cooperative games", Ann. Math., Second Series, vol. 54, no. 2, pp. 286-295, 1951. [http://dx.doi.org/10.2307/1969529]

[27] N. Howard, Paradoxes of Rationality: Theory of Metagames and Political Behavior., MIT Press: Cambridge, Mass, USA, 1971.

[28] P. Bennett, "Toward a theory of hypergames", Omega, vol. 5, no. 6, pp. 749-751, 1977. [http://dx.doi.org/10.1016/0305-0483(77)90056-1]

[29] N.S. Kovach, A.S. Gibson, and G.B. Lamont, "Hypergame theory: a model for conflict, misperception, and deception", Game Theory, vol. 2015, pp. 1-20, 2015.

[http://dx.doi.org/10.1155/2015/570639]

[30] Nancy, "China News weekly Changzhou a school and a critical transformation of key areas, " In NEWS HUB OF GOLDEN BRIC, 2016. Available at: http://www.hubgold.com/2016/05/09/china-news-weekly-changzhou-a-school-and-a-critical-transformation-of-key-areas/.

[31] C. Campbell, 500 Chinese kids sick from toxic waste dumped by high school. Time Magazine, 2016. Available at: http://time.com/4298774/china-public-health-toxic-chemicals-pollution-jiangsu-changzhou/

[32] X. Qinduo, Toxic schools raise 'love canal' spectre in The Global Times, The Global Times, 2016. Available at: http://www.globaltimes.cn/content/979223.shtml

[33] K.W. Hipel, and A. Dagnino, "A hypergame algorithm for modeling misperceptions in bargaining", J. Environ. Manage., vol. 27, pp. 131-152, 1988 .

[34] K. Madani, and K. W. Hipel, "Non-cooperative stability definitions for strategic analysis of generic water resources conflicts", Water Resour. Manage., vol. 25, no. 8, pp. 1949-1977, 2011. [http://dx.doi.org/10.1007/s11269]

\section{(C) 2017 Ali et al.}

This is an open access article distributed under the terms of the Creative Commons Attribution 4.0 International Public License (CC-BY 4.0), a copy of which is available at: (https://creativecommons.org/licenses/by/4.0/legalcode). This license permits unrestricted use, distribution, and reproduction in any medium, provided the original author and source are credited. 